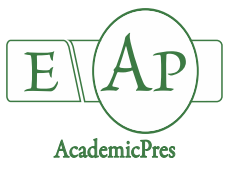

Chen C-C et al. (2021)

Notulae Botanicae Horti Agrobotanici Cluj-Napoca

Volume 49, Issue 1, Article number 12127

DOI: $10.15835 /$ nbha49112127

Research Article

\title{
Water-use efficiency and nitrogen uptake in rice seedlings grown under different light quality
}

\section{Chang-Chang CHEN ${ }^{\text {la }}$, Wen-Dar HUANG ${ }^{2 b}$, Zhi-Wei YANG ${ }^{3}$, Chi-Ming YANG ${ }^{4 *}$, Karyne M. ROGERS ${ }^{5,6 *}$}

\author{
${ }^{1}$ National Research Institute of Chinese Medicine, Ministry of Health and Welfare, Beitou 11221, Taipei, Taiwan; \\ chencc@nricm.edu.tw \\ 2Department of Agronomy, National Taiwan University, Daan 10617,Taipei, Taiwan; wendar@ntu.edu.tw \\ ${ }^{3}$ Taoyuan District Agricultural Research and Extension Station, Council of Agriculture, Executive Yuan, Sinwu 32745, Taoyuan, \\ Taiwan; zwyang@tydais.gov.tw \\ ${ }^{4}$ Biodiversity Research Center, Academia Sinica, Nankang 11529, Taipei, Taiwan; \\ cmyang@gate.sinica.edu.tw (*co-corresponding author) \\ 5Institute of Quality and Standards for Agricultural Products, Zhejiang Academy of Agricultural Sciences, Hangzhou, 310021, China \\ ${ }^{6}$ National Isotope Centre, GNS Science, 30 Grace field Road, Lower Hutt, 5040, New Zealand; \\ K.Rogers@gns.cri.nz (*corresponding author) \\ ${ }^{a, b}$ These authors contributed equally to the work
}

\section{Abstract}

Rice (Oryza sativa L.) cultivars 'Taichung shen 10' ('TCS10') and 'IR1552' were hydroponically grown under different light conditions to investigate the effect of light quality on their biomass, transpiration, wateruse efficiency (WUE), carbon isotope discrimination $(\Delta)$, seed nitrogen $(\mathrm{N})$ contribution and nitrogen uptake ability from the hydroponic nutrient solutions. Light emitting diode (LED) lighting systems were used to control light quality. Different light treatments were applied to the rice seedlings including red $(R)$, green $(G)$, and blue light (B), with red + blue light (RB) as control. The photon flux density was set at $105 \mu \mathrm{mol} \mathrm{m} \mathrm{s}^{-2} \mathrm{~s}^{-1}$. WUE and $\Delta$ were combined to evaluate whole-plant WUE. Improved whole-plant WUE was observed for both cultivars under $\mathrm{R}$ and $\mathrm{RB}$ light due to lower transpiration rates than under $\mathrm{B}$ light. Green light also improved $\Delta$ in both rice seedling cultivars. Seed $N$ contribution of both cultivars was stable across all light treatments, while improved $\mathrm{N}$ uptake ability was observed under $\mathrm{B}$ and $\mathrm{RB}$ light. In addition, $\mathrm{N}$ uptake in 'IR1552' rice seedling cultivars did not respond as favourably to green light as 'TCS10' cultivars.

Keywords: carbon isotope discrimination; light quality; nitrogen uptake; rice seedling; water-use efficiency

\section{Introduction}

Optimization of lighting environment is one major challenge to promote availability for plant production in green house or plant factory (Rehman et al., 2017; Zou et al, 2020). Lighting environment, including the light spectrum, intensity, and photoperiod, regulates plant morphogenesis, plant photosynthetic differentiation and growth (Hughes, 1981). Among the spectral range of photosynthetically active radiation 
(400 - $700 \mathrm{~nm}$ ), red and blue light plays a large role in plant growth because these wavelengths are the principal energy sources for plant photosynthesis (McCree, 1971; Yang et al., 2017). Recently, green light has also been reported to contribute to photosynthesis in plants (Smith et al., 2017). For optimization of lighting environment, light-emitting diodes (LEDs) provide light within the required narrow spectrum for plant photosynthesis, morphogenesis, and growth (Rehman et al., 2017), and allows an evaluation of the spectrum composition necessary to provide optimal plant production conditions (Zou et al., 2020). Different spectral light induces distinct morphogenetic and photosynthetic responses that vary depending on plant species and/or cultivars (Chen et al., 2014; Clavijo-Herrera et al., 2018). At a gaseous exchange level, red, blue, and green light serves as an environmental signal to mediate $\mathrm{CO}_{2}$ assimilation and water transpiration via regulation of stomatal opening (Inoue and Kinoshita, 2017; Smith et al., 2017).

Water-use efficiency (WUE), defined as the ratio of dry matter or yield produced to water transpired or irrigated, is considered an important attribute for growth (Farquhar et al., 1982; Farquhar et al., 1989). On shorter-time scales, transpiration and/or photosynthesis rates in leaves respond to the light spectrum composition of the growing environment, and the intrinsic WUE dynamics (the ratio of net $\mathrm{CO}_{2}$ assimilation rate to $\mathrm{H}_{2} \mathrm{O}$ transpiration rate) also depends on light quality (Lee et al., 2007; Yang et al., 2016; Lanoue et al., 2017; Yang et al., 2017; Liu et al., 2018). On longer-time scales, whole-plant WUE (the ratio of plant biomass to amount of water used during the plant's entire growth cycle) is regulated by various combinations of red and blue light (Clavijo-Herrera et al., 2018; Pennisi et al., 2019). Carbon isotope discrimination ( $\Delta$ ), derived from the carbon isotope composition $\left(\delta^{13} \mathrm{C}\right)$, is an alternative screening technique for WUE and is highly correlated with transpiration efficiency. It has been demonstrated to be a simple but reliable method to determine WUE (Farquhar et al., 1989; Durand et al., 2020). The advantages of $\Delta$ includes ease and speed of measurements and that it integrates data over of the entire growth period (Condon et al., 1987).

Nitrogen-use efficiency, defined as the dry matter or grain yield produced per unit of $\mathrm{N}$ applied, is determined from two plant physiological components, namely efficiency of $\mathrm{N}$ uptake and $\mathrm{N}$ utilization (Xu et al., 2012). Root architecture and nitrate reductase activity are both related to the plant root's ability to obtain $\mathrm{N}$ from soil, nutrient solution, or growth medium, and are regulated by blue light (Sasakawa and Yamamoto, 1979; Lin and Sauter, 2018). Several studies have reported N uptake dynamics of plants grown under various ratios of red and blue light (Shi et al., 1999; Clavijo-Herrera et al., 2018; Pennisi et al., 2019). Green light also promotes enzyme activity which promotes $\mathrm{N}$ uptake and assimilation (Bian et al., 2018). The red: far-red light ratio also influences nitrogen content in leaves (Frak et al., 2002). Dalal et al. (2013) suggested that inherent differences in the nitrogen isotope composition $\left(\delta^{15} \mathrm{~N}\right)$ of different $\mathrm{N}$ sources (such as soil and fertilizer) can be used to estimate the relative contribution of each $\mathrm{N}$ source to the total crop $\mathrm{N}$ uptake. A stable nitrogen isotope approach is considered a useful phenotyping tool for evaluation of $\mathrm{N}$ uptake in plants (Hu and Guy, 2020).

Our previous research found that light quality may mediate the photosynthetic potential and nitrogen uptake/metabolism in 'Taichung shen 10' ('TCS10') and 'IR1552' rice seedlings (Chen et al., 2014), thus we assume that light quality might control whole-plant WUE and N uptake in seedlings of these two cultivars. Increasingly, plant factories grow intensively farmed vegetables and fruits produced under artificial lights, especially in areas with high population densities and limited agricultural land. In this follow-up study, we investigate the effect of light quality on WUE and N uptake of rice seedlings using a stable isotope approach. The outcome of this study will contribute to further efficiencies for the provision of high-quality seedlings and will enable increased plant health and crop yields for intensively farmed produce.

\section{Materials and Methods}

\section{Plant and growth conditions}

Seeds from two rice (Oryza sativa L.) cultivars ('TCS10' and 'IR1552') were sterilized with 2\% sodium hypochlorite for 20 mins, washed extensively with distilled water, and germinated in Petri dishes on wet filter 
paper at $37^{\circ} \mathrm{C}$ in the dark. After 48 hours of incubation, 30 uniformly germinated seeds were selected and cultivated in a $150 \mathrm{ml}$ beaker containing half-strength Kimura B nutrient solution ( $\mathrm{pH} 4.7$ ) which was prepared according to our previous study (Chen et al., 2014). Nutrient solutions were replaced every 3 days. Hydroponically grown rice seedlings were raised in growth chambers under LED lights at $30^{\circ} \mathrm{C}$ day $/ 25^{\circ} \mathrm{C}$ night temperatures with a 12-hour photoperiod. Hydroponically grown seedlings were collected on day 14 after reaching stage V2 or V3 according to Counce et al. (2000). The shoots and roots of the seedlings were separated and freeze-dried before analysis.

\section{Light treatments}

The LED light system, designed by GRE Technology (Taipei, Taiwan), was electronically controlled to mediate the light spectrum composition. Spectral distributions of blue (peak at $460 \mathrm{~nm}$ ), red (peak at $630 \mathrm{~nm}$ ), and green (peak at $530 \mathrm{~nm}$ ) light were measured using a spectro-radiometer (LI-COR1800, Lincoln, NE, USA) in the 300-800 $\mathrm{nm}$ range. Light treatments for rice seedlings consisted of red LED (R), green LED (G), blue LED (B), and a mixture of red plus blue LED (R:B = 4:1 by photon flux density; RB). Photosynthetic photon flux density (PPFD) was uniformly set at $105 \mu \mathrm{mol} \mathrm{m}^{-2} \mathrm{~s}^{-1}$.

\section{Measurements}

The same initial starting volume of nutrient solution was used in each hydroponic beaker, and the water loss from each beaker recorded before each nutrient solution top-up. Control beakers (without seedlings) were placed under each light source to determine evaporation rates. The volume of transpired water from seedlings over 3 days was calculated by the difference in volume between beakers with and without rice seedlings.

The dry matter content (DM) of the lyophilized shoots and roots were weighed, and the seedling biomass (BM) was calculated as the total weight of dry matter in seedlings, including the shoot and roots. Total water transpiration $(T)$ in seedlings was determined by the amount of transpired water from each beaker during the 14-day experiment. Water-use efficiency (WUE), defined as the ratio of biomass in seedlings to total water transpiration was calculated as the following equation (Sinclair et al., 1984):

$$
\text { WUE }\left(\mathrm{mg} \mathrm{DM} \mathrm{g}^{-1} \mathrm{H}_{2} \mathrm{O}\right)=\mathrm{BM}(\mathrm{mg} \text { DM per beaker }) / \mathrm{T}\left(\mathrm{g} \mathrm{H}_{2} \mathrm{O} \text { per beaker }\right)
$$

Lyophilized shoots and seeds of both cultivars were ground to a fine, homogeneous powder by a Tissuelyser homogenizer (Qiagen Ltd, Germany). The relative carbon and nitrogen isotopic ratios $\left(\delta^{13} \mathrm{C}\right.$ and $\delta^{15} \mathrm{~N}$ values), and $\% \mathrm{C}$ and $\% \mathrm{~N}$ of the rice seedlings (shoot part) were measured. $\delta^{15} \mathrm{~N}$ values and $\% \mathrm{~N}$ of nutrient sources; $\mathrm{KNO}_{3},\left(\mathrm{NH}_{4}\right)_{2} \mathrm{SO}_{4}$, and $\mathrm{Ca}\left(\mathrm{NO}_{3}\right)_{2}$ used to manufacture the nutrient solution were also determined. Samples were analyzed in duplicate at the Stable Isotope Laboratory, GNS Science, New Zealand, using a VG Isoprime (Isoprime Ltd, UK) isotope ratio mass spectrometer, interfaced to a EuroVector elemental analyser (EuroVector Ltd, Italy) in continuous flow mode (EA-IRMS). Results were expressed in conventional delta notation $(\delta)$, defined as \%o, according to the following equation (Peterson and Fry, 1987):

$$
\delta(\%)=\left[\left(\mathrm{R}_{\text {sample }}-\mathrm{R}_{\text {standard }}\right) / \mathrm{R}_{\text {standard }}\right] \times 1000(\%)
$$

where $R_{\text {sample }}$ and $R_{\text {standard }}$ are the fractions of heavy to light isotopes in the sample and standard, respectively. The raw isotope data were corrected for linearity and stretching using working reference materials (leucine, cane sugar, caffeine, beet sugar, Buffalo River sediment, San Joaquin soil) calibrated to international standards (IAEA-N1, IAEA-N2, IAEA-CH6 and IAEA-CH7) and were reported relative to Vienna Pee Dee Belemnite for carbon (VPDB) and atmospheric air for nitrogen. Carbon isotope discrimination $(\Delta)$ was calculated as the following equation:

$$
\Delta(\% 0)=\left[\left(\delta^{13} \mathrm{C}_{\text {air }}-\delta^{13} \mathrm{C}_{\text {sample }}\right) /\left(1000+\delta^{13} \mathrm{C}_{\text {sample }}\right)\right] \times 1000(\% 0)
$$

where $\delta^{13} C_{\text {air }}=-8.4 \%$ (Dombrosky, 2020).

$\delta^{15} \mathrm{~N}$ values of rice seedling shoots and nutrient solution were compared with a similar study (Dalal et al., 2013). The $\delta^{15} \mathrm{~N}$ values of different nutrient sources are listed in Table 1 . The $\delta^{15} \mathrm{~N}$ value of the nutrient solution $\left(\delta^{15} \mathrm{~N}_{\mathrm{NS}}\right)$ was calculated from the molecular formula of the nutrient solution and the $\delta^{15} \mathrm{~N}$ value of three contributing nitrogen sources $\left(\mathrm{KNO}_{3},\left(\mathrm{NH}_{4}\right)_{2} \mathrm{SO}_{4}\right.$, and $\left.\mathrm{Ca}\left(\mathrm{NO}_{3}\right)_{2}\right)$. Total seedling $\mathrm{N}\left(\mathrm{N}_{\mathrm{T}}\right)$ was calculated 
from $\% \mathrm{~N}$ of seedling and shoot biomass. $\mathrm{N}$ content of rice seedlings derived from rice seed $\left(\mathrm{N}_{\text {seed }}\right)$ and the nutrient solution $\left(\mathrm{N}_{\mathrm{NS}}\right)$ were evaluated from $\delta^{15} \mathrm{~N}$ using models as the following equations:

$$
\begin{aligned}
& \mathrm{N}_{\text {seed }}(\mathrm{mgN} \text { per beaker })=\mathrm{N}_{\mathrm{T}} \times\left(\delta^{15} \mathrm{~N}_{\text {sample }}-\delta^{15} \mathrm{~N}_{\mathrm{NS}}\right) /\left(\delta^{15} \mathrm{~N}_{\text {seed }}-\delta^{15} \mathrm{~N}_{\mathrm{NS}}\right) \\
& \mathrm{N}_{\mathrm{NS}}(\mathrm{mg} \mathrm{N} \text { per beaker })=\mathrm{N}_{\mathrm{T}} \times\left(\delta^{15} \mathrm{~N}_{\text {seed }}-\delta^{15} \mathrm{~N}_{\text {sample }}\right) /\left(\delta^{15} \mathrm{~N}_{\text {seed }}-\delta^{15} \mathrm{~N}_{\mathrm{NS}}\right)
\end{aligned}
$$

Table $1 . \delta^{15} \mathrm{~N}$ and $\mathrm{N}$ content $(\% \mathrm{~N})$ of two rice cultivar seedlings and three nitrogenous fertilizer sources used to manufacture the nutrient solution, and the estimated $\delta^{15} \mathrm{~N}$ value of the nutrient solution used in this study

\begin{tabular}{|c|c|c|}
\hline Nitrogen source & $\delta^{15} \mathrm{~N}(\%)$ & \% N \\
\hline 'TCS10' seed & 4.7 & 1.4 \\
\hline 'IR1552' seed & 8.9 & 2.2 \\
\hline $\mathrm{KNO}_{3}$ & 3.1 & 13.8 \\
\hline$\left(\mathrm{NH}_{4}\right)_{2} \mathrm{SO}_{4}$ & -9.4 & 21.5 \\
\hline $\mathrm{Ca}\left(\mathrm{NO}_{3}\right)_{2}$ & -1.0 & 11.9 \\
\hline Nutrient solution (NS) & -4.3 & - \\
\hline
\end{tabular}

$\delta^{15} \mathrm{~N}$ value of nutrient solution (NS) was calculated from the formula of the nutrient solution and $\delta^{15} \mathrm{~N}$ values of three contributing nitrogen sources.

\section{Statistical analysis}

All measurements were evaluated for significance using an analysis of variance (ANOVA) followed by a least significant difference (LSD) test at the $p<0.05$ level. All statistical analyses were conducted using proc GLM from SAS 9.3 (SAS Institute, Cary, NC, USA). A correlation analysis was conducted to relate BM, T, WUE and $\Delta$ followed by a Pearson correlation analysis using proc CORR from SAS 9.3.

\section{Results}

\section{Biomass, transpiration of water, and water-use efficiency}

$\mathrm{BM}, \mathrm{T}$, and WUE in both cultivar seedlings under different light quality are presented in Figure 1. BM is the total shoot and root dry matter from the 14-day-old seedlings (Figure 1A). BM of 'TCS10' seedlings collected from under different LED lighting environments ranged from 254 to $262 \mathrm{mg}$ DM per beaker, and the difference among all treatments was insignificant. 'IR1552' seedlings grown under B had the most biomass out of all the other LED light types, with $209 \mathrm{mg}$ DM per beaker.

Seedling $\mathrm{T}$ was calculated from water lost through transpiration every 3 days in each beaker (Figure 1B). T in 'TCS10' seedlings responded to different LED light quality. The highest T in 'TCS10' seedlings was 174.7 $\mathrm{g} \mathrm{H}_{2} \mathrm{O}$ per beaker under $\mathrm{B}$, the second highest was $159.0 \mathrm{~g} \mathrm{H}_{2} \mathrm{O}$ per beaker under $\mathrm{RB}$, and the lowest was 132.7 and $144.0 \mathrm{~g} \mathrm{H}_{2} \mathrm{O}$ per beaker under $\mathrm{R}$ and $\mathrm{G}$, respectively. The highest $\mathrm{T}$ for 'IR1552' seedlings was $70.3 \mathrm{~g} \mathrm{H}_{2} \mathrm{O}$ per beaker, under $\mathrm{B}$.

WUE was calculated from total biomass and water transpiration from each beaker (Figure 1C). WUE of 'TCS10' seedlings collected from $\mathrm{R}$ was $5.00 \mathrm{mg} \mathrm{DM} \mathrm{g}^{-1} \mathrm{H}_{2} \mathrm{O}$, significantly higher $(p<0.05)$ than $\mathrm{B}$ and $\mathrm{RB}$. The highest WUE in 'IR1552' seedlings was $7.12 \mathrm{mg} \mathrm{DM} \mathrm{g}^{-1} \mathrm{H}_{2} \mathrm{O}$ under $\mathrm{R}$, and the lowest WUE, $3.93 \mathrm{mg} \mathrm{DM}$ $\mathrm{g}^{-1} \mathrm{H}_{2} \mathrm{O}$, was determined from seedlings grown under $\mathrm{B}$.

\section{Carbon isotope discrimination}

Carbon isotope discrimination $(\Delta)$, calculated from $\delta^{13} \mathrm{C}$ of seedlings (Table 2) and atmospheric $\mathrm{CO}_{2}$ (defined as $-8.4 \%$ ), also responded to different light quality (Figure 2). $\Delta$ of both cultivars showed a similar response to different light quality. $\Delta$ of both cultivars collected from B (24.1 and 26.0\%o for 'TCS10' and 'IR1552', respectively) were significantly higher $(p<0.05)$ than other light treatments, and the next highest was under RB (23.5\% and 24.8\%o). The lowest $\Delta$ for both cultivars were observed under $\mathrm{R}$ and G. 


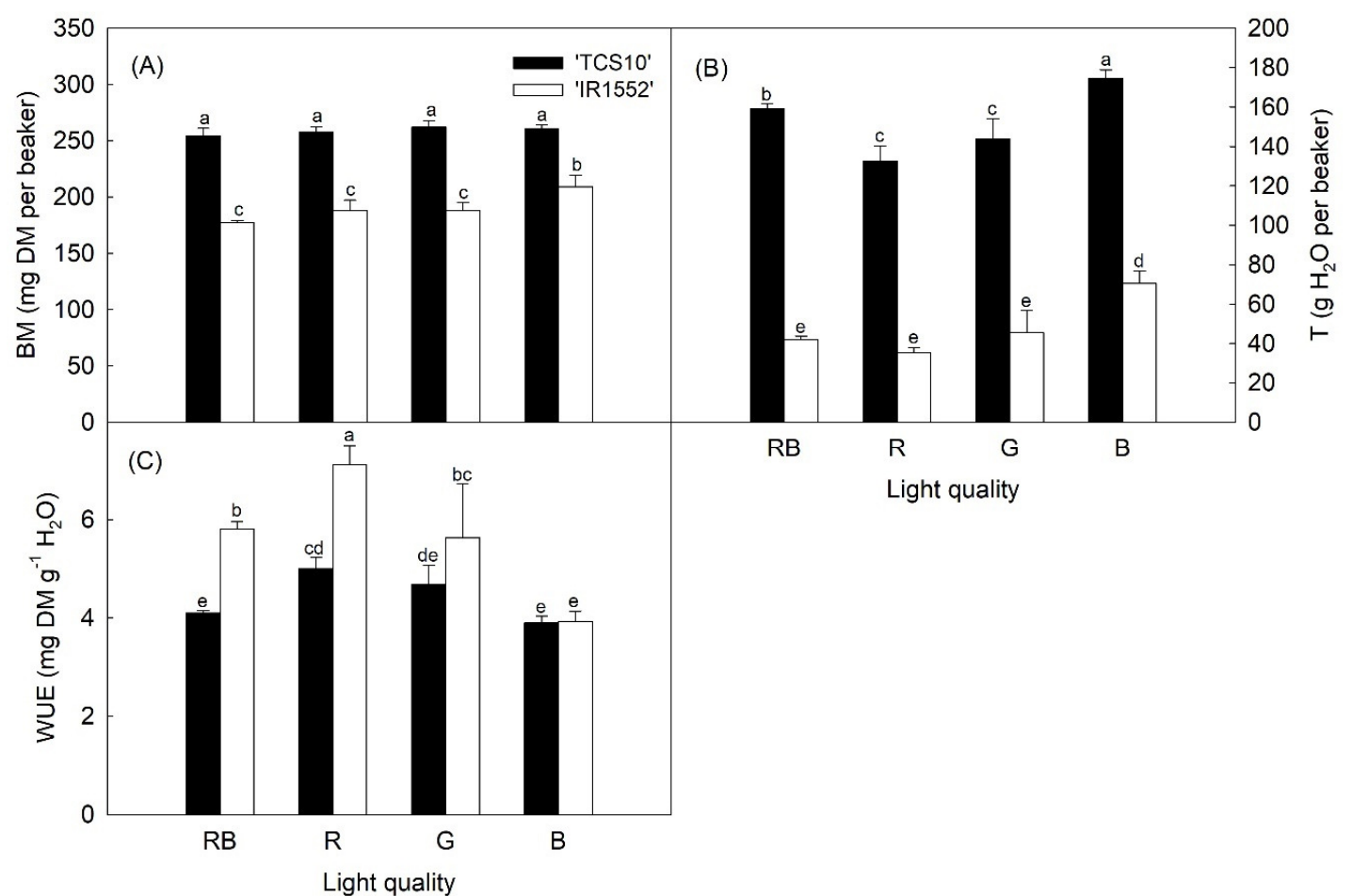

Figure 1. (A) Biomass (BM), (B) transpiration (T), and (C) water-use efficiency (WUE) in 'TCS10' and 'IR1552' rice cultivars under different light quality

Values represent the mean of three replicate samples. The values followed by the different letters show statistically significant differences according to LSD $(p<0.05)$. RB -mixture of red plus blue, R - red; G - green; B - blue.

Table 2. $\delta^{13} \mathrm{C}, \% \mathrm{~N}$, and $\delta^{15} \mathrm{~N}$ values of rice cultivar seedlings 'TCS10' and 'IR1552' under different light quality

\begin{tabular}{|c|c|c|c|c|}
\hline Cultivar & Light quality & $\delta^{13} \mathrm{C}(\% \mathrm{o})$ & $\delta^{15} \mathrm{~N}(\% 0)$ & $\% \mathrm{~N}$ \\
\hline \multirow{4}{*}{ 'TCS10' } & $\mathrm{RB}$ & $-30.8 \pm 0.0$ & $-0.9 \pm 0.1$ & $4.5 \pm 0.1$ \\
\cline { 2 - 5 } & $\mathrm{R}$ & $-30.4 \pm 0.1$ & $-0.6 \pm 0.2$ & $4.4 \pm 0.0$ \\
\cline { 2 - 5 } & $\mathrm{G}$ & $-30.2 \pm 0.0$ & $-0.9 \pm 0.1$ & $4.4 \pm 0.1$ \\
\cline { 2 - 5 } & $\mathrm{B}$ & $-31.4 \pm 0.1$ & $-1.0 \pm 0.1$ & $4.4 \pm 0.0$ \\
\cline { 2 - 5 } & $\mathrm{RB}$ & $-32.0 \pm 0.2$ & $3.8 \pm 0.2$ & $6.0 \pm 0.1$ \\
\cline { 2 - 5 } & $\mathrm{R}$ & $-31.5 \pm 0.1$ & $4.2 \pm 0.3$ & $5.5 \pm 0.1$ \\
\cline { 2 - 5 } & $\mathrm{G}$ & $-31.5 \pm 0.2$ & $4.2 \pm 0.2$ & $5.5 \pm 0.0$ \\
\hline
\end{tabular}

Each value represents mean $\pm S E(n=3)$; RB -mixture of red plus blue, $R$ - red; $G$ - green; $B$ - blue.

Relationships between $\Delta$ and BM, T, and WUE for both cultivars collected from different light quality were analyzed (Figure 3). $\Delta$ was significantly correlated with biomass $(\mathrm{r}=0.647, p<0.05)$ for cultivar 'IR1552', but uncorrelated for 'TCS10' (Figure 3A). However, there was a strong positive relationship between $\Delta$ and T in 'TCS10' $(\mathrm{r}=0.851, p<0.001)$ and 'IR1552' $(\mathrm{r}=0.836, p<0.001)$ (Figure 3B). Moreover, $\Delta$ was negatively correlated with WUE for both cultivars $(\mathrm{r}=-0.785, p<0.01)$ (Figure 3C). 


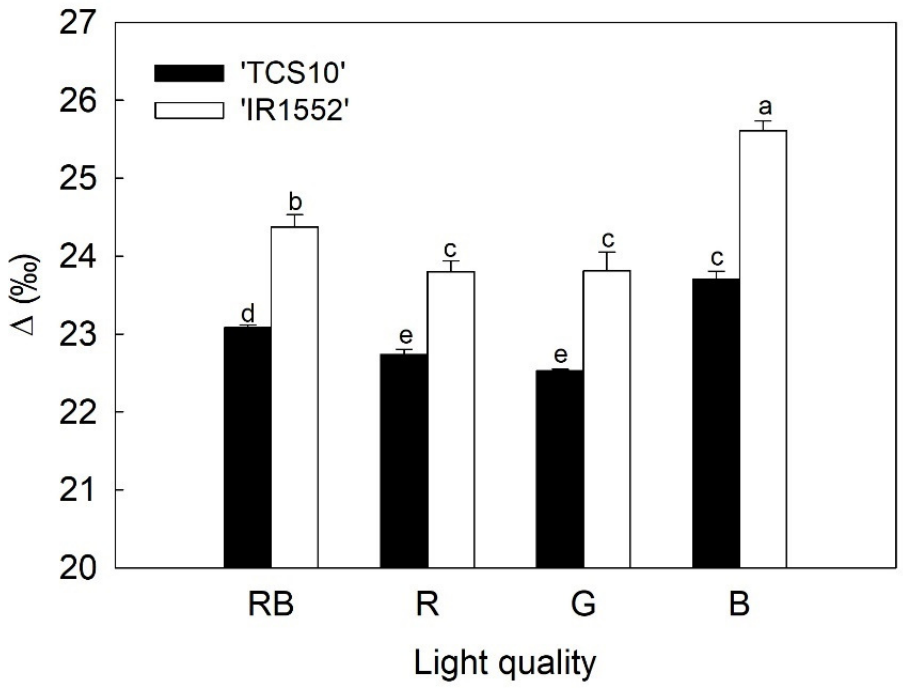

Figure 2. Carbon isotope discrimination $(\Delta)$ in 'TCS10' and 'IR1552' rice cultivars under different light quality

Values represent the mean of three replicate samples. The values followed by the different letters show statistically significant differences according to LSD $(p<0.05)$. RB -mixture of red plus blue, R - red; G - green; B - blue.

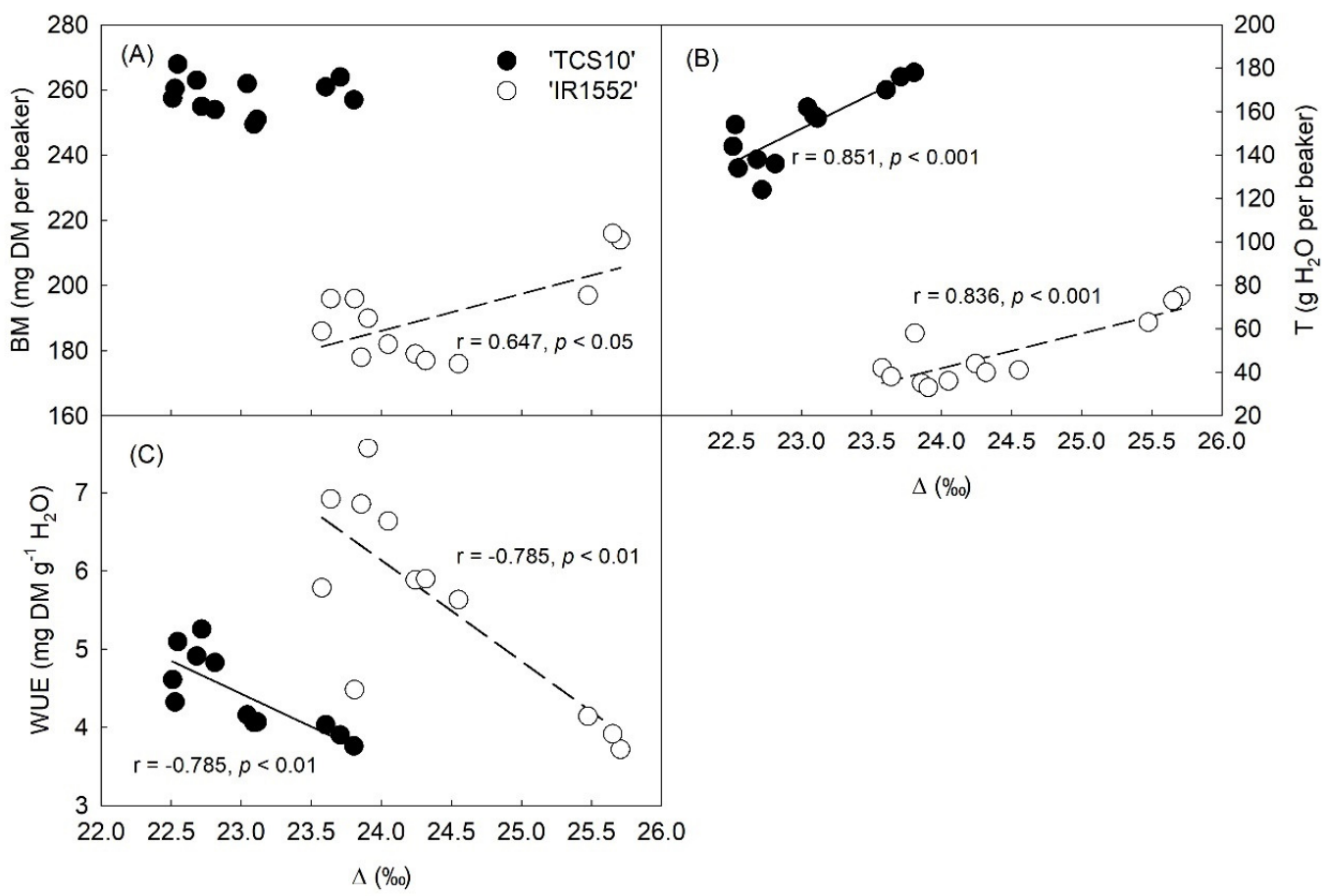

Figure 3. Relationships between $\Delta$ and (A) biomass (BM), (B) transpiration (T), (C) and water-use efficiency (WUE) for 'TCS10' and 'IR1552' rice cultivars under different light quality

\section{Seed $N$ contribution and nutrient solution $N$}

Mean $\% \mathrm{~N}$ and $\delta^{15} \mathrm{~N}$ values in both cultivar seedlings collected from different light quality are listed in Table 2. Both seed $\mathrm{N}$ contribution $\left(\mathrm{N}_{\text {seed }}\right)$ and nutrient solution $\mathrm{N}\left(\mathrm{N}_{\mathrm{NS}}\right)$ usage are calculated from $\% \mathrm{~N}$ and $\delta^{15} \mathrm{~N}$ values according to Dalal et al. (2013) and are plotted in Figure 4. $\mathrm{N}_{\text {seed }}$ for seedlings raised under different 
light types were similar for both cultivars and ranged from 4.2 to $4.6 \mathrm{mg} \mathrm{N}$ per beaker, and 6.4 to $6.7 \mathrm{mg} \mathrm{N}$ per beaker for 'TCS10' and 'IR1552', respectively (Figure 4A). Less $\mathrm{N}_{\mathrm{NS}}$ was used by the 'TSC10' cultivar under R ( $6.7 \mathrm{mg} \mathrm{N}$ per beaker) than under other light types ( 7.2 to $7.3 \mathrm{mg} \mathrm{N}$ per beaker). Furthermore, the highest $\mathrm{N}_{\mathrm{NS}}$ used by the 'IR1552' cultivar was $6.4 \mathrm{mg} \mathrm{N}$ per beaker under B, followed by $4.1 \mathrm{mg} \mathrm{N}$ per beaker under RB, the lowest amount was 3.7 and $3.7 \mathrm{mg} \mathrm{N}$ per beaker, respectively under $\mathrm{R}$ and $\mathrm{G}$ (Figure $4 \mathrm{~B}$ ).

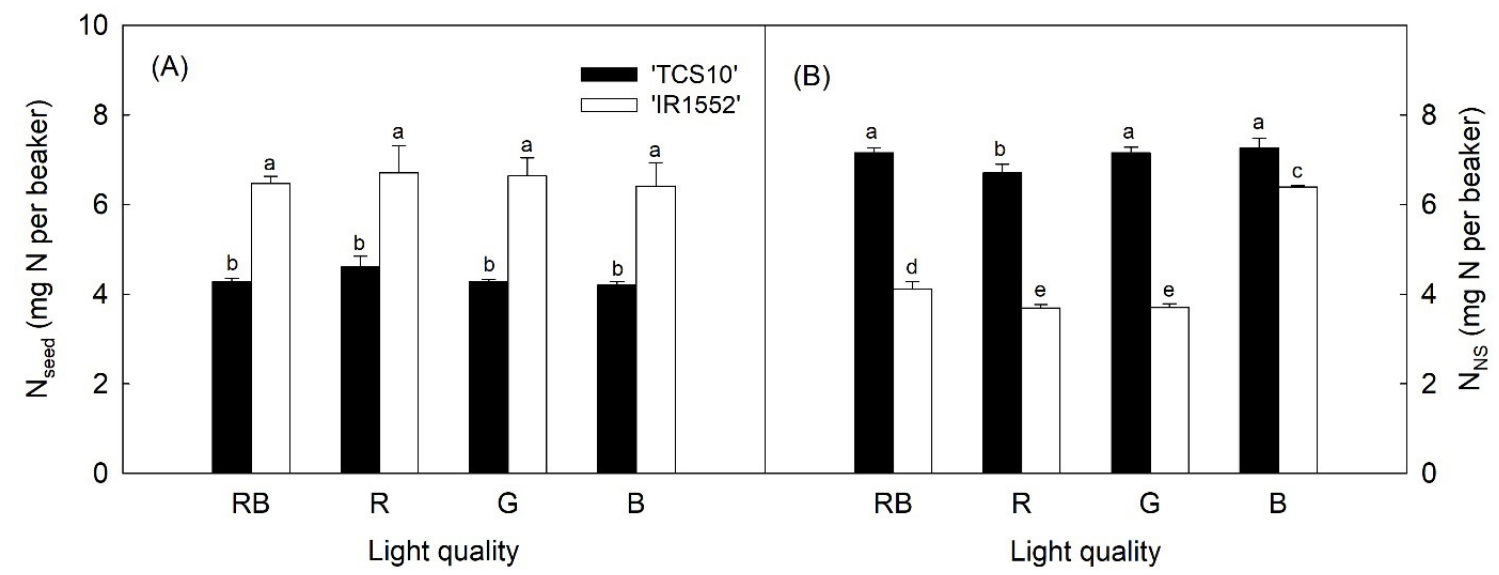

Figure 4. Seed $\mathrm{N}$ contribution to seedling $\left(\mathrm{N}_{\text {seed }}\right)$ and nutrient solution $\mathrm{N}\left(\mathrm{N}_{\mathrm{NS}}\right)$ of 'TCS10' and 'IR1552' rice cultivars under different light quality

Values represent the mean of three replicate samples. The values followed by the different letters show statistically significant differences according to LSD $(p<0.05)$. RB -mixture of red plus blue, R - red; G - green; B - blue.

\section{Discussion}

Stomatal responsiveness mediates both $\mathrm{CO}_{2}$ uptake and $\mathrm{H}_{2} \mathrm{O}$ transpiration in leaves and results in different WUE dynamics (Lawson and Blatt, 2014). Red light provides the energy source for the photosynthetic reaction which mediates stomatal opening, whereas blue light is directly absorbed by phototropins which trigger signaling pathways to regulate stomatal opening and control gaseous exchange (Inoue and Kinoshita, 2017). Over different time scales, WUE can be determined by photosynthesis and transpiration in leaves or be evaluated from the ratio of total biomass or yield produced divided by the amount of water used during crop life cycle (Farquhar et al., 1982; Farquhar et al., 1989). Previous studies have reported that water transpiration in leaves of Cyclocarya paliurus (Lee et al., 2007), Withania somnifera (Liu et al., 2018), purple cabbage (Yang et al., 2016), tomato (Solanum lycopersicum) (Lanoue et al., 2017) and tobacco (Nicotiana tabacum) (Yang et al., 2017) was significantly increased under B light, while photosynthesis rates did not increase with higher transpiration rates. Meanwhile, intrinsic WUE was found to significantly increase at the leaf level due to lower transpiration under red light (Lee et al., 2007; Lanoue et al., 2017).

In this study, inherent ${ }^{13} \mathrm{C}$ differences were observed for both rice cultivars grown under different light conditions (Table 1). The results suggested that $\Delta$ presented a negative correlation to whole-plant WUE (Figure 3) and was considered an effective tool for screening WUE dynamics (Condon., 1987; Farquhar et al., 1989; Durand et al., 2020). Likewise, various $\Delta$ responses to different light treatments in seedlings were observed (Figure 2). Seedling BM was similar among all light treatments, while lower $\mathrm{T}$ was measured under red light (Figure 1). Therefore, whole-plant WUE in seedlings was enhanced under red light LED (Figures 1 and 2). Moreover, $\mathrm{T}$ and $\Delta$ in seedlings of both cultivars grown under $\mathrm{R}+\mathrm{B}$ were lower than $\mathrm{B}$. Results from this study were similar to previous studies which demonstrated whole-plant WUE in lettuce (Lactuca sativa) (Clavijo-Herrera et al., 2018) and sweet basil (Ocimum basilicum) (Pennisi et al., 2019) was increased under red-enriched environments. 
Green light which is adsorbed less by photosynthetic pigments from plant tissue, as well as blue and red light, serve as an environmental signal to optimize stoma aperture and to fine-tune photosynthesis and transpiration in plants (Smith et al., 2017). In this study, a lower seedling T was determined under green light, and it also caused improved whole-plant WUE (Figures 1 and 2). Previous studies in Cyclocarya paliurus (Liu et al., 2018), purple cabbage (Yang et al., 2016), tobacco (Yang et al., 2017), and tomato (Lanoue et al., 2017) also indicated that transpiration rates in leaves were significantly inhibited under green light. Several studies have shown that enhanced whole-plant WUE was accompanied by lower transpiration rates and/or inhibited stomatal conductance (Lee et al., 2007; Lanoue et al., 2017; Clavijo-Herrera et al., 2018; Pennisi et al., 2019). Consequently, lower transpiration rates equate to better whole-plant WUE, including where WUE (Figure 1) and $\Delta$ (Figure 2) of seedlings grown under $\mathrm{R}$ and $\mathrm{G}$ might be caused by light-regulated stomatal opening. The correlation between $\Delta$ and $\mathrm{T}$ also suggested that improved whole-plant WUE arose from lower transpiration rates rather than higher biomass accumulation (Figure 3).

Nitrogen use in plants is determined from $\mathrm{N}$ uptake, translocation, assimilation, and sequential remobilization, and is governed by several genetic and environmental factors and their interactions (Xu et al., 2012). Light quality, a key environmental factor, also regulates nitrogen use in plant. Previous studies of rice reported that blue light more effectively induced nitrate reductase activity and mediated development of adventitious roots, but red light was found to increase nitrate uptake only slightly (Sasakawa and Yamamoto, 1979; Lin and Sauter, 2018). Recent research on lettuce revealed green light induced nitrate reductase, nitrite reductase, glutamine synthetase, and glutamate synthase activities (Bian et al., 2018).

$\delta^{15} \mathrm{~N}$ can be used to evaluate nitrogen uptake (Dalal et al., 2013) and/or assimilation (Hu and Guy, 2020). In this study, $\mathrm{N}_{\text {sed }}$ and seedling $\mathrm{N}_{\mathrm{NS}}$ was evaluated according to the inherent $\delta^{15} \mathrm{~N}$ differences in the seed, nutrient solution (Table 1), and seedlings (Table 2). Seed $\mathrm{N}$ contribution $\left(\mathrm{N}_{\text {seed }}\right)$ was extremely stable for both cultivars (Figure 4). Total N of 'TCS10' and 'IR1552' seeds was 8.4 and $10.5 \mathrm{mg}$ per beaker, respectively. Therefore, 'TCS10' and 'IR1552' seeds provided between 61-64 and 50-55\% respectively of the $\mathrm{N}$ required for shoot development during the 14-day experiment. Conversely, $\mathrm{N}_{\mathrm{NS}}$ of both cultivars was reduced under $\mathrm{R}$ compared to $\mathrm{B}$ (Figure 4). Furthermore, enhanced $\mathrm{N}_{\mathrm{NS}}$ under $\mathrm{RB}$ seen in this research suggested more $\mathrm{N}$ uptake in seedlings, consistent with previous studies in tobacco (Shi et al., 1999) and sweet basil (Pennisi et al., 2019). However, Clavijo-Herrera et al. (2018) indicated that light quality was ineffective in regulating nitrogen uptake in lettuce. In this study, root biomass from neither of the two rice cultivars grown under RB increased under B light (data not shown), therefore the increase of $\mathrm{N}$ uptake under $\mathrm{R}+\mathrm{B}$ light might be attributed to nitrate activity regulation and root architecture (Sasakawa and Yamamoto, 1979; Lin and Sauter, 2018). Additionally, 'TCS10' and 'IR1552' seedlings showed a divergent response for $\mathrm{N}$ uptake under green light in this study which may reflect an opposing sensitivity to green light (Figure 4).

\section{Conclusions}

Our study showed blue light promoted water transpiration, leading to a decline in WUE and effectively promoting $\mathrm{N}$ uptake in rice seedlings. Red light successfully inhibited water transpiration, and green light also mediated WUE similar to R light. There are significant implications from this research for the burgeoning plant factory industry where crops are grown continually all year using indoor farming techniques and artificial light. We propose that by supplementing growing conditions with moderate exposure to mono-spectral light, improved water-use efficiency (less transpiration) and higher nitrogen uptake can be promoted in plants. In this study, we also demonstrated that stable $\mathrm{C}$ and $\mathrm{N}$ isotope techniques can estimate water use and nitrogen uptake in two rice cultivars ('IR1552' and 'TCS10' seedlings) to assess crop physiology. $\Delta$ values can be a useful tool to evaluate whole-plant WUE, while higher $\delta^{15} \mathrm{~N}$ values reflect increased nutrient uptake efficiency of fertilizers, providing a measure of efficiency and sustainability. 


\section{Authors' Contributions}

Conceptualization: CCC and WDH; Data curation: CCC and WDH; Formal analysis: CCC and WDH; Investigation: CCC, WDH, and ZWY; Methodology: WDH, CMY and KMR; Project administration: WDH, CMY and KMR; Resources: WDH, ZWY, CMY and KMR; Software: CCC; Supervision: CMY and KMR; Validation: CMY and KMR; Visualization: CCC; Writing - original draft: CCC and WDH; review and editing: CMY and KMR. All authors read and approved the final manuscript.

\section{Acknowledgements}

This research received no specific grant from any funding agency in the public, commercial, or not-forprofit sectors. We thank Dr. Su-Jein Chang (Miaoli District Agricultural Research and Extension Station) for donation of 'IR1552'. Thanks also to Andy Philips and SImon Stewart of the Stable Isotope Laboratory at GNS Science, New Zealand.

\section{Conflict of Interests}

The authors declare that there are no conflicts of interest related to this article.

\section{References}

Bian Z, Cheng R, Wang Y, Yang Q, Lu C (2018). Effect of green light on nitrate reduction and edible quality of hydroponically grown lettuce (Lactuca sativa L.) under short-term continuous light from red and blue lightemitting diodes. Environmental and Experimental Botany 153:63-71. https://doi.org/10.1016/j.envexpbot.2018.05.010

Chen CC, Huang MY, Lin KH, Wong SL, Huang WD, Yang CM (2014). Effects of light quality on the growth, development and metabolism of rice seedlings (Oryza sativa L.). Research Journal of Biotechnology 9(4):15-24. https://worldresearchersassociations.com/Archives/RJBT/Vol(9)2014/April2014.aspx

Clavijo-Herrera J, Van Santen E, Gómez C (2018). Growth, Water-use efficiency, stomatal conductance, and nitrogen uptake of two lettuce cultivars grown under different percentages of blue and red light. Horticulturae 4(3):16. https://doi.org/10.3390/horticulturae4030016

Condon AG, Richards RA, Farquhar GD (1987). Carbon isotope discrimination is positively correlated with grain yield and dry matter production in field-grown wheat. Crop Science 27:996-1001. https://doi.org/10.2135/cropsci1987.0011183X002700050035X

Counce PA, Keisling TC, Mitchell AJ (2000). A uniform, objective, and adaptive system for expressing rice development. Crop Science 40:436-443. https://doi.org/10.2135/cropsci2000.402436x

Dalal RC, Strong WM, Cooper JE, King AJ (2013). Relationship between water use and nitrogen use efficiency discerned by ${ }^{13} \mathrm{C}$ discrimination and ${ }^{15} \mathrm{~N}$ isotope ratio in bread wheat grown under no-till. Soil and Tillage Research 128:110-118. https://doi.org/10.1016/j.still.2012.07.019

Dombrosky J (2020). A $\sim 1000$-year ${ }^{13} \mathrm{C}$ Suess correction model for the study of past ecosystems. The Holocene 30(3):474-478. https://doi.org/10.1177/0959683619887416

Durand M, Brendel O, Buré C, Courtois P, Lily JB, Granier A, Le Thiec D (2020). Impacts of a partial rainfall exclusion in the field on growth and transpiration: consequences for leaf-level and whole-plant water-use efficiency compared to controlled conditions. Agricultural and Forest Meteorology 282-283:107873. https://doi.org/10.1016/j.agrformet.2019.107873

Farquhar GD, Ehleringer JR, Hubick KT (1989). Carbon isotope discrimination and photosynthesis. Annual Review of Plant Physiology and Plant Molecular Biology 40:503-537. https://doi.org/10.1146/annurev.pp.40.060189.002443 
Farquhar GD, O'Leary MH, Berry JA (1982). On the relationship between carbon isotope discrimination and the intercellular carbon dioxide concentration in leaves. Functional Plant Biology 9:121-137. https://doi.org/10.1071/PP9820121

Frak E, Le Roux X, Millard P, Adam B, Dreyer E, Escuit C, ... Varlet-Grancher C (2002). Spatial distribution of leaf nitrogen and photosynthetic capacity within the foliage of individual trees: disentangling the effects of local light quality, leaf irradiance, and transpiration. Journal of Experimental Botany 53(378):2207-2216. https://doi.org/10.1093/jxb/erf065

$\mathrm{Hu}$ Y, Guy RD (2020). Isotopic composition and concentration of total nitrogen and nitrate in xylem sap under near steady-state hydroponics. Plant, Cell and Environment 43:2112-2123. https://doi.org/10.1111/pce.13809

Hughes KW (1981). In vitro ecology: Exogenous factors affecting growth and morphogenesis in plant culture systems. Environmental and Experimental Botany 21:281-288. https://doi.org/10.1016/0098-8472(81)90038-1

Inoue S, Kinoshita T (2017). Blue light regulation of stomatal opening and the plasma membrane $\mathrm{H}^{+}$-ATPase. Plant Physiology 174(2):531-538. https://doi.org/10.1104/pp.17.00166

Kang WH, Park JS, Park KS, Son JE (2016). Leaf photosynthetic rate, growth, and morphology of lettuce under different fractions of red, blue, and green light from light-emitting diodes (LEDs). Horticulture, Environment, and Biotechnology 57:573-579. https://doi.org/10.1007/s13580-016-0093-X

Lanoue J, Leonardos ED, Ma X, Grodzinski B (2017). The effect of spectral quality on daily patterns of gas exchange, biomass gain, and water-use-efficiency in tomatoes and lisianthus: An assessment of whole plant measurements. Frontiers in Plant Science 8:1076. https://doi.org/10.3389/fpls.2017.01076

Lawson T, Blatt MR (2014). Stomatal size, speed, and responsiveness impact on photosynthesis and water use efficiency. Plant Physiology 164(4):1556-1570. https://doi.org/10.1104/pp.114.237107

Lee SH, Tewari RK, Hahn EJ, Paek KY (2007). Photon flux density and light quality induce changes in growth, stomatal development, photosynthesis and transpiration of Withania Somnifera (L.) Dunal. plantlets. Plant Cell, Tissue and Organ Culture 90:141-151. https://doi.org/10.1007/s11240-006-9191-2

Lin C, Sauter M (2018). Control of adventitious root architecture in rice by darkness, light, and gravity. Plant Physiology 176(2):1352-1364. https://doi.org/10.1104/pp.17.01540

Liu Y, Wang T, Fang S, Zhou M, Qin J (2018). Responses of morphology, gas exchange, photochemical activity of photosystem II, and antioxidant balance in Cyclocarya paliurus to light spectra. Frontiers in Plant Science 9:1704. https://doi.org/10.3389/fpls.2018.01704

McCree KJ (1971). The action spectrum, absorptance and quantum yield of photosynthesis in crop plants. Agricultural Meteorology 9:191-216. https://doi.org/10.1016/0002-1571(71)90022-7

Pennisi G, Blasioli S, Cellini A, Maia L, Crepaldi A, Braschi I, ... Gianquinto G (2019). Unraveling the role of red:blue LED lights on resource use efficiency and nutritional properties of indoor grown sweet basil. Frontiers in Plant Science 10:305. https://doi.org/10.3389/fpls.2019.00305

Peterson BJ, Fry B (1987). Stable isotopes in ecosystem studies. Annual Review of Ecology and Systematics 18(1):293320. https://doi.org/10.1146/annurev.es.18.110187.001453

Rehman M, Ullah S, Bao Y, Wang B, Peng D, Liu L (2017). Light-emitting diodes: whether an efficient source of light for indoor plant? Environmental Science and Pollution Research 24:24743-24752. https://doi.org/10.1007/s11356-017-0333-3

Sasakawa H, Yamamoto Y (1979). Effects of red, far red, and blue light on enhancement of nitrate reductase activity and on nitrate uptake in etiolated rice seedlings. Plant Physiology 63(6):1098-1101. https://doi.org/10.1104/pp.63.6.1098

Shi H, Han J, Guan C, Yuan T (1999). Effects of red and blue light proportion on leaf growth, carbon-nitrogen metabolism and quality in tobacco. Acta Agronomica Sinica 25(2):213-220 (in Chinese with English abstract). http://en.cnki.com.cn/Article_en/CJFDTotal-XBZW199902012.htm

Sinclair TR, Tanner CB, Bennett JM (1984). Water-use efficiency in crop production. BioScience 34(1):36-40. https://doi.org/10.2307/1309424

Smith HL, McAusland L, Murchie EH (2017). Don't ignore the green light: exploring diverse roles in plant processes. Journal of Experimental Botany 68(9):2099-2110. https://doi.org/10.1093/jxb/erx098

Xu G, Fan X, Miller AJ (2012). Plant nitrogen assimilation and use efficiency. Annual Review of Plant Biology 63(1):153182. https://doi.org/10.1146/annurev-arplant-042811-105532 
Yang B, Zhou X, Xu R, Wang J, Lin Y, Pang J, ... Zhong F (2016), Comprehensive analysis of photosynthetic characteristics and quality improvement of purple cabbage under different combinations of monochromatic light. Frontiers in Plant Science 7:1788. https://doi.org/10.3389/fpls.2016.01788

Yang LY, Wang LT, Ma JH, Ma ED, Li JY, Gong M (2017). Effects of light quality on growth and development, photosynthetic characteristics and content of carbohydrates in tobacco (Nicotiana tabacum L.) plants. Photosynthetica 55(3):467-477. https://doi.org/10.1007/s11099-016-0668-X

Zou T, Huang C, Wu P, Ge L, Xu Y (2020). Optimization of artificial light for spinach growth in plant factory based on orthogonal test. Plants 9:490. https://doi.org/10.3390/plants9040490
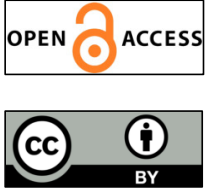

The journal offers free, immediate, and unrestricted access to peer-reviewed research and scholarly work. Users are allowed to read, download, copy, distribute, print, search, or link to the full texts of the articles, or use them for any other lawful purpose, without asking prior permission from the publisher or the author.

License - Articles published in Notulae Botanicae Horti Agrobotanici Cluj-Napoca are Open-Access, distributed under the terms and conditions of the Creative Commons Attribution (CC BY 4.0) License. (c) Articles by the authors; UASVM, Cluj-Napoca, Romania. The journal allows the author(s) to hold the copyright/to retain publishing rights without restriction. 